\title{
Priscol in the Treatment and Prevention of Leprosy Deformities
}

\author{
J. S. MATHUR, M.D., D.P.H.(Lond.), F.R.I.P.H.H.(Lond.) \\ Reader in Social and Preventive Medicine, College of Medical Sciences, Banaras Hindu University, Varanasi \\ and \\ K. N. SAXENA, M.D., D.T.M.\&H. \\ Reader in Skin and V.D., S. N. Medical College, Agra
}

Leprosy is a very serious problem in most of the South Asian countries. They have on an average five to ten leprosy patients per i, ooo population. In some places its incidence is as high as 30 to 50 per I,ooo. WHO Expert Committee on Leprosy ( I 960) estimated that 25 per cent of all leprosy patients suffer from some degree of physical disability. Various permanent disabilities and crippling defects are the usual outcome of this disease. The handicapped leprosy patients become a burden on society. In the absence of any other occupation, many of them become mendicants. Loss to a country is in terms of physical and moral suffering, deprivation of economic and productive labour, and financial outlays on social and welfare activities (Hemerijckx I96I).

Modern medicine has made tremendous progress in the treatment of leprosy. During the last Ioo years almost every type of drug and surgical manoeuvre has been tried for the cure and prevention of this dreadful disease and its manifestations, but only a few of them are considered really effective. In spite of the use of these drugs physical defects in leprosy patients continue to occur. Surgical correction, physiotherapy and splintage of anaesthetic fingers and toes in the treatment of leprosy are not without risk. Even with splintage and physiotherapy the fingers tend to go back to their original position. It is against the principles of surgery to operate for reconstructive surgery with an open wound on the part. Moreover for reconstructive surgery in leprosy, properly trained orthopaedic and plastic surgeons are required. To restore the hand to some degree of usefulness a series of tendon transplant operations need to be performed. In India the number of leprosy patients is very large and only few hospitals are taking an active interest in reconstructive surgery.

\section{Material and Method}

Eighteen patients of neural leprosy aged 22 to 74 years with varying degree of deformities and contractures of fingers and thumb were studied from leprosy hospitals of Varanasi and outpatient department of S.N. Hospital, Agra. Clinical and laboratory diagnosis of leprosy was made. All these patients were receiving antileprosy treatment for the last four to eight years in leprosy hospitals. They noticed even after anti-leprosy treatment for few years, a gradual increase in the degree of deformities and contracture of fingers and thumb, wasting of hand muscles and varying degree of loss of sensations for touch, temperature and pain on the hand and forearm. A weekly record in the improvement and experience of various symptoms was kept. The patients are still receiving the same therapy for the improvement and prevention of any more deformities and contractures.

Priscol I ml. (Tolazoline hydrochloride) was injected twice a week in the ulnar nerve in ulnar groove by the technique used by Saxena and Mathur (1963). These patients were also kept under antileprosy treatment and were given sulphones. A weekly record of degree of improvement noticed and felt was kept. Photographs of initial deformities and contractures of fingers and after receiving priscol treatment for one and a half to two months were taken to judge the degree of improvement in deformities and contractures. In six patients, priscol injection has been stopped and they are now kept only on sulphones in follow up of two months. The rest of the $\mathrm{I} 2$ patients are still under the priscol and sulphone therapies.

The deformities and contracture of fingers were classified as severe and moderate, depending on the degree of deformity of fingers, involvement of number of fingers and their 
use in daily work. Severe deformities and contractures involve more than one finger and their incapacitation to an extent where they cannot be used even for every day work. Moderate deformities and contractures may involve one or more fingers but they remain useful to some extent for day-to-day work.

Response to this therapy was noted as excellent, beneficial, or poor, judging by considering the overall improvement of fingers and hand, improvement in the degree of deformity and contractures and the regaining in varying degree of lost sensations. Results are described 'excellent' when the hand and fingers can be used for fine work and the patient allowed to return to the old profession. There is considerable improvement in the power of the hand and return in sensations for touch, temperature, and pain nearly towards normal. Fingers had almost straightened. Results are classified as 'beneficial' when the hand and fingers can be used only for routine work. Sensations return from 50 to 75 per cent but they do not become normal. In poor results the patient can use the hand a little more but not freely so as to perform dayto-day work. There is slight improvement in the degree of deformity with or without slight improvement in the degree of sensation.

TABLE I

Severe and Moderate deformities and contractures

\begin{tabular}{|c|c|c|c|c|c|c|c|c|c|c|c|}
\hline \multirow[t]{2}{*}{ Type } & \multicolumn{2}{|c|}{$\begin{array}{l}\text { Total Number } \\
\text { of cases }\end{array}$} & \multicolumn{3}{|c|}{$\begin{array}{c}\text { Number of Fingers } \\
\text { Involved }\end{array}$} & & \multicolumn{4}{|c|}{$\begin{array}{l}\text { Degree of deformity and number of } \\
\text { fingers in each group }\end{array}$} & \multirow{2}{*}{$\begin{array}{l}\text { Number of } \\
\text { cases with } \\
\text { usefulness } \\
\text { of fingers }\end{array}$} \\
\hline & & Small & Ring & Middle & Index & Thumb & $0-45^{\circ}$ & $4^{6-90^{\circ}}$ & $9^{1-1} 45^{\circ}$ & $146-180^{\circ}$ & \\
\hline $\begin{array}{l}\text { Severe deformity } \\
\text { and contractures }\end{array}$ & I 2 & I 2 & I 2 & 9 & 6 & 3 & 8 & 7 & I 3 & 14 & $\begin{array}{l}\text { To some } \\
\text { extent in } \\
\text { one only }\end{array}$ \\
\hline $\begin{array}{l}\text { Moderate deformity } \\
\text { and contractures }\end{array}$ & 6 & 6 & 4 & - & - & - & IO & - & - & - & 6 \\
\hline
\end{tabular}

Deformities and Contractures before and after the treatment

\begin{tabular}{|c|c|c|c|c|c|c|c|c|c|c|c|c|c|}
\hline \multirow[t]{2}{*}{ Type } & \multirow{2}{*}{\multicolumn{2}{|c|}{ S. No. }} & \multirow{2}{*}{$\begin{array}{c}\text { Duration of } \\
\text { illness in } \\
\text { years }\end{array}$} & \multicolumn{5}{|c|}{$\begin{array}{c}\text { Degree of Contractures of digits before } \\
\text { treatment }\end{array}$} & \multicolumn{5}{|c|}{ Degree of contractures after treatment } \\
\hline & & & & $L$ & $R$ & $M$ & $I$ & $T$ & $L$ & $R$ & $M$ & $I$ & $T$ \\
\hline & & GAR & 7 & I 75 & I 65 & I6o & I6o & I 20 & 95 & 70 & 70 & 70 & I \\
\hline & 2 & LR & 6 & 160 & I IO & I IO & II 5 & - & $6 o$ & o & o & I5 & - \\
\hline & 3 & ML & 6 & I 20 & IIO & II 5 & 115 & 40 & 30 & 15 & I 5 & Io & Io \\
\hline & 4 & MSL & 6 months & I 75 & I 70 & 30 & - & - & o & o & o & - & - \\
\hline Severe & 5 & MS & 6 months & I 70 & 170 & 30 & - & - & o & o & o & - & - \\
\hline \multirow[t]{7}{*}{ deformities } & 6 & GAR & 8 & I6o & I 60 & I 50 & I6o & I 35 & IIO & 90 & 90 & IOO & 70 \\
\hline & 7 & LRR & 6 & 140 & 80 & 80 & 85 & - & 30 & 25 & 15 & I 5 & - \\
\hline & 8 & $\mathrm{SN}$ & 4 & $5^{0}$ & 20 & IO & - & - & o & o & o & - & - \\
\hline & 9 & $\mathrm{BP}$ & 6 months & 55 & 45 & - & - & - & IO & o & - & - & - \\
\hline & IO & $\mathrm{S}$ & 5 & 95 & 95 & - & 一 & 一 & 35 & 30 & 一 & 一 & 一 \\
\hline & I I & MZ & 7 & 130 & IOO & IOO & 90 & - & 50 & 40 & 40 & 30 & - \\
\hline & I 2 & G & $2 \frac{1}{2}$ & 70 & 45 & - & - & 一 & 50 & 25 & - & - & - \\
\hline \multirow{6}{*}{$\begin{array}{l}\text { Moderate } \\
\text { deformities }\end{array}$} & & $\mathrm{M}$ & 2 & & 20 & - & 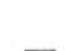 & 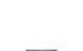 & 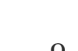 & 0 & - & $\pi$ & - \\
\hline & 2 & $\mathrm{~S}$ & 6 months & $\begin{array}{l}40 \\
30\end{array}$ & I 5 & - & - & - & o & o & - & - & - \\
\hline & 3 & $\mathrm{Jg}$ & 2 & 25 & - & - & - & - & o & o & - & - & - \\
\hline & & Jw & I & 30 & - & - & - & - & o & - & - & 一 & - \\
\hline & 5 & $\mathrm{~J}$ & 6 months & 35 & 25 & - & - & - & o & o & - & - & - \\
\hline & 6 & $\mathrm{P}$ & 1 & 30 & 20 & - & - & - & 5 & o & - & - & - \\
\hline
\end{tabular}




\section{RESULTS}

All the patients felt lightness of hand and forearm on the first day after first priscol injection. For the first two to four injections, eight patients felt pin-pricks in forearm and hand, while four patients complained of sense of heaviness in the injected limb. The degree of improvement varied in different patients after a number of priscol injections were given. Generally there was apparent improvement in sensations, degree of deformity, and contractures, power of hand and movement of fingers after four to six priscol injections. Table I shows the distribution of cases of severe and moderate deformity and contractures.

All the patients regained usefulness of fingers and hands. The ulnar nerve was painful

Case I. M.S. Aged 20 years complained of loss of sensation, deformities of little, ring and middle fingers (Fig. I), ulcer on the dorsum of the ring finger and wasting of muscles for the last one year. He had been receiving antileprosy treatment for the last six years. The hand was swollen for the last two to three months. He was treated continuously with intraneural priscol along with sulphones. After six priscol injections sensations in completely lost area returned to normal, swelling of the hand subsided, deformity started improving and ulcers healed. With eight injections of priscol the skin colour returned to normal and hair growth appeared and with 14 to 17 injections the contracture of the fingers improved (Fig. 2). Priscol has been stopped for the last two months. He is receiving only antileprosy drugs.
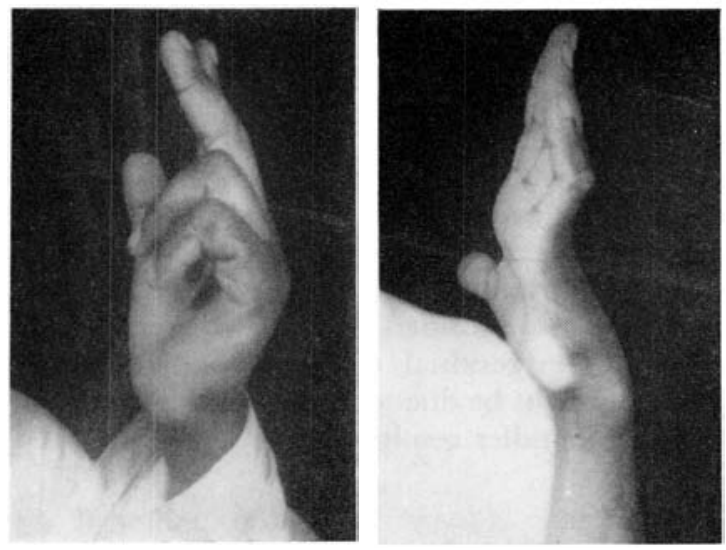

Fig. I. Deformities of fingers and hand before priscol therapy. Fig. 2. Improvement in deformities of fingers and hand after priscol therapy. to touch in 5 patients and pain along the ulnar nerve was complained of by four patients. The nerve became less painful after priscol injections and pain along the nerve subsided in two patients while in the other two pain subsided to the extent of 75 per cent.

Table 2 shows the degree of deformities and contractures of fingers in all the patients before and after priscol therapy. Degree of deformity and contracture was measured at the metacarpo-phalangeal joints. Out-stretched hand was taken at $\mathrm{O}^{\circ}$ to $\mathrm{I} 8 \mathrm{O}^{\circ}$ axis and right angled flexed fingers at $90^{\circ} .0^{\circ}$ was at the tip of small finger of stretched hand and proximal medial end of the hand was taken at $180^{\circ}$ angle.

The response to treatment in all the 8 cases is shown in Table 3 .

Case 2. G.D.M. Aged 32 years complained of loss of sensation, wasting of hand muscles, deformities and contractures of all the fingers of hand for the last seven years (Fig. 3). He had ulcers at the interphalangeal joints of middle, ring and index fingers. He had been on antileprosy treatment for the last eight years. After eight to ten priscol injections, the deformities improved (Fig. 4), power in wasted hand muscles improved, ulcers at interphalangeal joint healed early and skin elasticity returned. Contractures at the interphalangeal joints now interfere with the further extension of fingers. He is still receiving priscol and antileprosy treatment.
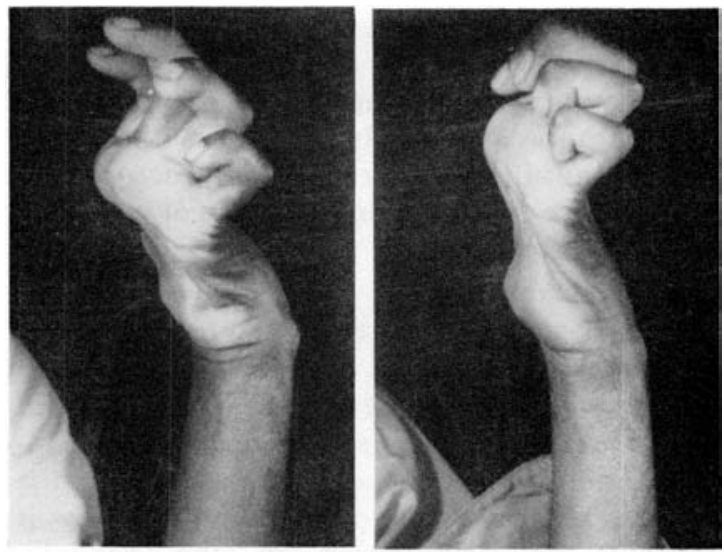

Fig. 3. Deformities of all the fingers and hand before priscol therapy. Fig. 4. Improvement in deformities after to priscol injections. 
TABLE III

\begin{tabular}{lc|cc}
\multicolumn{1}{c}{ Type of cases } & $\begin{array}{c}\text { Total } \\
\text { number }\end{array}$ & & Response to therapy \\
\cline { 3 - 4 } & & Excellent & Beneficial Poor \\
\hline Severe deformities and contractures & I 2 & 9 & 2 \\
Moderate deformities and contractures & 6 & 6 & - \\
\hline
\end{tabular}

DISCUSSION

One of the features of leprosy is its predilection for peripheral nerves. Degree of dysfunction from the lesions of these nerves varies from loss of sensation to deformities, contractures and loss of organs. The ulnar is the commonest nerve involved in polyneuritic cases. In the present series it was affected in all the patients. The contracture of small finger in all the cases had occurred earliest and was followed by the involvement of ring and other fingers and thumb. In cases with longer duration of illness more and more digits were involved.

Intraneural priscol improved earlier the deformities of ring, middle, index finger and thumb. The response in small finger was delayed and was not of the same magnitude as noted with other fingers.

All the patients in the severe group had adhesions of skin of small finger and some patients of a few other fingers also due to contractures at interphalangeal joints or adhesions followed ulcers. These contractures and adhesions of skin were more marked at middle and terminal interphalangeal joints. They were responsible for poor improvement in cases with beneficial and poor results. The adhesions of skin as well as early involvement of small finger appear to be the reason for poor and delayed improvement. In patients with moderate degree of deformities and contractures the improvement with intraneural priscol was early and complete.

Saxena and Mathur ( 1963 ) have shown in their earlier work that neural signs and symptoms of leprosy have a close relationship with the blood supply of the nerves to the affected part. Priscol has a local spreading and vasodilatory action on the blood vessels supplying the affected part and the nerves and thereby it improves the circulation in the partially ischaemic nerve bundles. Long continued ischaemic changes over years degenerate the nerve bundles resulting in varying degree of irreversible damage and loss of function. In the present series patients with longer and severe contractures did not show complete recovery. In two of the patients there was complete correction in the contracture of index and middle fingers after four priscol injections.

Saxena and Mathur ( 1963) observed vascular involvement in leprosy and reported warming of cold skin of the hand, return of healthy skin colour, growing of hairs and return of venous prominence in hand. Similar observations were made by Chatterjee (I 955). Cochrane (I959) found sensory, motor and trophic changes in the parts supplied by the partial ischaemic nerve bundles. Chatterjee (I 955) reported correction of deformities in some of the patients with the improvement of blood supply.

Priscol has no systemic effect on leprosy. Oral and systemic administrations were tried but they did not show any improvements in the degree of deformities and contractures or anaesthesia. Intraneural priscol injections given in one limb did not improve deformities, contractures and lost sensations in the other limbs.

Improvements were more rapid in the initial stages of priscol therapy. Muscular contractures, strength of hand muscles, and anaesthesia continued to improve even after the skin lesions had subsided. Wasted muscles of the hand showed considerable improvement and the depressions caused by wasted dorsal interrossei and lumbricals improved. Chatterjee (I955) considered residual abnormality after the skin reactions had subsided to the fibrosis inside the nerves. The residual deformities after priscol therapy might be due to fibrosis or degeneration of nerve bundles resulting from long continued ischaemia.

Khanolkar (1955) and the editorial in Leprosy in India (1953) considered ascending degeneration of nerves in leprosy. It is difficult to explain on this assumption the present improvement of deformities, muscle strength and 
anaesthesia in such a short time with priscol therapy. Normally nerve after injury regenerates at a rate of 3 to $4 \mathrm{~mm}$. in a day. Chatterjee ( I 955) found it difficult to explain clinical signs on the basis of nerve degeneration.

Krogh (I929) and Lewis ( I 927) have shown that capillaries can contract independently of one another and of arterioles. Chatterjee (I 955) considered vascular constriction responsible for wasting and deformity in leprosy. In chronic lesions of leprosy there is gradual constriction of blood vessels of nerves and tissues causing gradual wasting, paralysis of muscles, deformities and contractures. The constriction of blood vessels inside nerve fibres may not be uniform all over and may affect various nerve fibres differently. The work of Crutz et al. (I 93 I, i 933), Goheen ( r 933), Chatterjee (r 955), Lowe and Chatterjee (I 937), Sharpey-Schafer and Wallace (1942) and Saxena and Mathur ( I 963) points towards the affection of vascular supply to the nerves in leprosy. Denny-Brown and Brenner (r 944), Causey and Palmer (r949), and Cochrane (r959), found morphological changes similar to Wallerian degeneration of nerves on being relatively partial ischaemic due to pressure. They also found complete morphological and functional restitution on restoring blood supply.

\section{S U M M A R Y}

Twelve leprosy patients with severe deformities and contractures and six with moderate deformities and contractures were given intraneural priscol in conjunction with standard antileprosy treatment. All the i 8 cases except the three with severe deformities and contractures showed excellent response. The three patients with severe deformities and contracture also showed improvement and results in them were beneficial but mild. Priscol corrects early deformities completely and prevents further development of deformities and contractures.

\section{A CKNOWLEDGEMENT}

I a m extremely thankful to CIBA of India Ltd. for supplying priscol ampoules for the trial on leprosy patients.

\section{REFERENCES}

causey, g. and palmer, e. (1 949). J. Physiol., rog, 220. Chatter Jee, s. N. (1 955). Int. 7. Leprosy, 23, I, I-I 8. cochrane, R. G. (I959). Leprosy in Theory and Practice, Wright, Bristol.

Grutz, m. c., AbUel, J. I. and samson, J. G. (I 933). Leprosy, India, 5, $5^{\mathrm{I}}$.

GRUtz, m. c., abuel, J. I. and samson, J. G. (ig3 I). $\mathcal{F}$. Philippine Islands Med. Assoc., I1, 474-476.

Denny-Brown, D. and Brenner, c. (1944), Arch. Neurol. Psychiat., 52, $\mathrm{I}$.

Editorial. (1952). Leprosy, India, 24, 35-45. GOHEen, R. H. (I 933 ). Leprosy, India, 5, 4-5. hemerijckx. (i 96 I). Med Ed. Bull., VI, 2, i6-i 9. KHANOLKAR, v. R. (I 952). Leprosy, India, 24, 62-77. Krogh, A. (1 929). The Anatomy and Physiology of Capillaries 2nd ed., New Haven, Yale University Press.

LEWIS, T. (1927). The Blood vessels of the Human Skin and their responses, Shaw \& Sons Ltd., London.

Lowes, J. and chatterJee, s. N. (I 937). Leprosy, India, 9, I I 5-I 20 .

saxena, к. n. and mathur, J. s. (i 964). 7. Ind. Med. Assn., 42, 3, I 3 I -33.

Sharpey-SGhafer, E. P. and wallace, J. (I942). Brit. Med. 7., 2, 304-307.

WHO Expert Committee. (1960). Technical Report Series, No. I 89 . 